\title{
Atrial Natriuretic Factor in Chronic Obstructive Lung Disease with Pulmonary Hypertension \\ Physiological Correlates and Response to Peptide Infusion
}

\author{
Serge Adnot," Pierre Andrivet, * Pierre Etienne Chabrier, Jacques Piquet, ${ }^{\ddagger}$ Pascale Plas, ${ }^{5}$ Pierre Braquet," \\ Françoise Roudot-Thoraval, ${ }^{*}$ and Christian Brun-Buisson ${ }^{\ddagger}$ \\ *Département de Physiologie et Unité de Recherche de Physiologie Respiratoire, Institut National de la Santé et Recherche Medicale \\ Unité 296; 'Services de Réanimation Médicale, de Pneumologie, et Santé Publique, Hôpital Henri Mondor, \\ 94010 Creteil, France; ${ }^{\S}$ Institut Henri Beaufour Labs, Les Ulis 91952 France
}

\begin{abstract}
To investigate the physiological role of atrial natriuretic factor (ANF) in patients with hypoxic pulmonary hypertension secondary to chronic obstructive lung disease (COLD), we infused synthetic $\alpha$-human ANF in seven such patients, and investigated the physiological correlates to circulating peptide levels in 24 patients with COLD.

ANF infusion, at incremental rates of $0.01,0.03$, and 0.1 $\mu \mathrm{g} / \mathrm{kg} \cdot \mathrm{min}$, increased basal plasma immunoreactive (ir) ANF $(136 \pm 38 \mathrm{pg} / \mathrm{ml})$ by $3-, 10-$, and 26-fold, respectively, and reduced pulmonary artery pressure (from $33 \pm 3$ to $25 \pm 2 \mathrm{mmHg}$, $P<0.001$ ) and systemic arterial pressure (from $88 \pm 4$ to $79 \pm 4$ mmHg, $P<0.001)$ in a dose-related fashion. Cardiac index increased by $13.5 \%(P<0.01)$ while heart rate was unchanged. Cardiac filling pressures decreased at $0.1 \mu \mathrm{g} / \mathrm{kg} \cdot \mathrm{min}$ ANF. Pulmonary and systemic vascular resistance fell by $37 \%(P<$ $0.001)$ and $19 \%(P<0.001)$, respectively. Arterial oxygenation was impaired during ANF infusion, suggesting partial reversal of hypoxic pulmonary vasoconstriction. Plasma renin activity remained unchanged but aldosterone fell by $44 \%(P<0.01)$.

The levels of plasma irANF in 24 patients correlated directly with the degree of hemoconcentration $(r=0.67, P$ $<0.001)$, respiratory acidosis $(r=-0.65, P<0.001)$, and pulmonary hypertension $(r=0.52, P<0.01)$. The results suggest that ANF may serve as a potent pulmonary vasodilator involved in the circulatory homeostasis of patients with COLD.
\end{abstract}

\section{Introduction}

Atrial natriuretic factor (ANF) ${ }^{1}$ is a peptide released from the cardiac atria that exhibits potent diuretic, natriuretic, and vasoactive properties (1-4). The predominant stimulus that triggers ANF secretion from atrial myocytes is direct atrial stretch

Address reprint requests to Dr. Adnot, Inserm U. 296, Hôpital Henri Mondor, 8, Avenue du General Sarrail, 94010 Creteil, France.

Received for publication 16 February 1988 and in revised form 22 July 1988.

1. Abbreviations used in this paper: ANF, atrial natriuretic factor; $\mathrm{CI}$, cardiac index; COLD, chronic obstructive lung disease; HR, heart rate; $\mathrm{FEV}_{1}$, forced expiratory volume in $1 \mathrm{~s}$; FVC, forced vital capacity; ir, immunoreactive; PPA, pulmonary arterial pressure; PPAW, pulmonary arterial wedge pressure; PRA, right atrial pressure; PSA, systemic arterial pressure; PVR, pulmonary vascular resistance; SVR, systemic vascular resistance.

J. Clin. Invest.

(C) The American Society for Clinical Investigation, Inc.

0021-9738/89/03/0986/08 $\$ 2.00$

Volume 83, March 1989, 986-993
(5). In humans, evidence has been provided that volume overloading or other maneuvers that acutely increase atrial stretch provoke increase in ANF secretion (6-8), suggesting that ANF contributes to the renal responses to central blood volume expansion.

With the subsequent synthesis of ANF, in-depth investigation of the renal and vascular actions of the peptide in humans has become possible. Intravenous administration of ANF in normal subjects causes marked diuresis and natriuresis (9-14), mild hypotension $(12,14)$, and a decrease of plasma renin and aldosterone concentrations $(9,12)$. In patients with congestive heart failure, whose plasma levels of immunoreactive ANF are elevated $(9,15,16)$, exogenous ANF infusion improves cardiac performance by inducing peripheral vasodilation $(9,17)$, suggesting a cardiovascular action of the peptide.

Patients with chronic pulmonary artery hypertension also have high levels of circulating ANF that appear related to their increased pulmonary artery pressure and resistance (18). The physiological significance of this observation however, cannot be defined unless the effects of ANF on the human pulmonary vasculature are characterized. Experimental data suggest that ANF can exert pulmonary vasodilating activity. Specific binding sites for ANF have been demonstrated in the lung $(19,20)$ and extraction of circulating ANF occurs during its passage across the lung (21). Moreover, ANF induces relaxation of pulmonary arteries from various animal species, an effect that may result from intracellular cyclic GMP production $(22,23)$. Consistent with these observations, recent experimental data in dogs and pigs show that ANF infusion induces pulmonary vasodilation in the setting of acute hypoxic pulmonary hypertension $(24,25)$

These findings led us to the hypothesis that ANF could serve as an endogenous pulmonary vasodilator in humans, particularly in disease states. To assess this potential role of ANF, we investigated patients with chronic obstructive lung disease (COLD) because chronic hypoxic vasoconstriction is considered the primary cause of pulmonary hypertension in this disease.

We first examined the consequences of synthetic human ANF infusion on hemodynamics, gas exchange, ventilation, and plasma levels of renin activity and aldosterone in seven patients with severe COLD and pulmonary hypertension. To further investigate the physiologic determinants of ANF secretion in this disease, we measured plasma ANF concentrations in a larger series of patients with COLD of varying severity.

\section{Methods}

Study population. The study group consisted of 24 patients with advanced COLD. There were 22 men and 2 women ranging in age from 
37 to $79 \mathrm{yr}$. The diagnosis of COLD was established from a previous history of chronic bronchitis and evidence of chronic airflow limitation on standard pulmonary function tests, with a forced expiratory volume in $1 \mathrm{~s}\left(\mathrm{FEV}_{1}\right)$ less than $60 \%$ predicted and a ratio of $F E V_{1}$ to forced vital capacity $\left(\mathrm{FEV}_{1} / \mathrm{FVC}\right)<50 \%$. All patients experienced dyspnea on exertion but they were in a stable phase of their disease. The absence of electrocardiographic abnormalities suggesting ischemic left heart disease and the absence of echocardiographic left ventricular dysfunction were verified in each patient before the study. Several patients had a previous history of right heart failure but none had peripheral edema at the time of the study. Patients were continued on their maintenance therapy with oral and inhaled bronchodilators but no drug was taken during the immediate period preceding measurements. None of these patients received steroids. Three patients were being chronically treated with supplemental oxygen which was maintained during the study period. The protocol was approved by the Ethical Committee of our institution and informed consent was obtained from each patient before the study.

In these 24 patients, the following measurements were performed in the morning, after the patients had been supine and fasting overnight.

Hemodynamic measurements. In preparation for the study, an arterial line was inserted percutaneously into a radial artery and a SwanGanz pulmonary artery catheter (Edwards Laboratories, Inc., Santa Ana, CA) was inserted via the internal jugular or antecubital vein on the evening before the study. Systemic and pulmonary artery pressures were measured using Gould P50 pressure transducers, coupled to pressure modules and a Gould ES 1000 multichannel recorder (Gould Electronics, Ballainvilliers, France). All transducers were referenced to the mid-chest level with patients in the supine, semirecumbent position. Mean systemic (PSA) and pulmonary arterial (PPA) pressures were obtained by electronic integration. Pulmonary arterial wedge (PPAW) and right atrial pressure (PRA) were read at end expiration over at least three respiratory cycles. Cardiac output was determined by the thermal dilution method using a bedside Edwards 9520-A cardiac output computer, and each cardiac output value was taken as the mean of at least three determinations. Heart rate (HR) was measured from a continuously recorded electrocardiogram lead. Derived hemodynamic variables were calculated according to standard formulas: cardiac index $(\mathrm{CI})=$ cardiac output/body surface area (liter $\left./ \mathrm{m}^{2}\right)$; systemic vascular resistance index $(\mathrm{SVR})=$ PSA - PRA $/ \mathrm{CI}(\mathrm{mmHg} /$ liter $\left.\cdot \min \cdot \mathrm{m}^{2}\right)$; pulmonary vascular resistance index $(\mathrm{PVR})=$ PPA - PPAW/CI $\left(\mathrm{mmHg} /\right.$ liter $\left.\cdot \mathrm{min} \cdot \mathrm{m}^{2}\right)$; stroke volume index (SVI) $=\mathrm{CI} / \mathrm{HR}\left(\mathrm{ml} /\right.$ beat $\left.\cdot \mathrm{m}^{2}\right)$.

Measurements of gas exchange and ventilation. Simultaneous arterial and mixed venous blood samples were collected in heparinized syringes for determination of blood gas tensions and pH (ABL 30; Radiometer, Copenhagen, Denmark). Total hemoglobin and hemoglobin oxygen saturation were measured by spectrophotometry, using an OSM 2 hemoximeter (Radiometer). Venous admixture (percentage of total blood flow) was calculated with the equation of Berggreen as capillary $\mathrm{O}_{2}$ content minus arterial $\mathrm{O}_{2}$ content/capillary $\mathrm{O}_{2}$ content minus mixed venous $\mathrm{O}_{2}$ content. Systemic oxygen transport was obtained from the product of cardiac index and arterial oxygen content, and reported in milliliters of $\mathrm{O}_{2}$ per minute.

Hormonal determinations. Hormonal measurements were performed on blood collected from the pulmonary artery. Samples were drawn on chilled EDTA tubes and centrifuged within $15 \mathrm{~min}$. Plasma samples were stored at $-30^{\circ} \mathrm{C}$ until they were processed.

PRA was indirectly determined by the generation of angiotensin I (angiotensin I radioimmunoassay kit; SB-Ren.2 Oris, Gif sur Yvette, France) and expressed as nanograms per milliliter per hour. The determination of plasma aldosterone was obtained using a radioimmunoassay kit (SB-Aldo; 2 Oris), and expressed as picograms per milliliter.

Plasma levels of immunoreactive (ir) ANF were measured from blood collected on EDTA tubes containing aprotinin $(1,000 \mathrm{KIU} / \mathrm{ml})$. The RIA used in this study has been previously described (18). The antibody was kindly provided by Dr. Cantin (Clinical Research Insti- tute of Montreal, Canada). Produced against the human 28 aminoacids $\mathrm{COOH}$-terminal peptide coupled to thyroglobulin, the antibody does not cross-react with nonrelated peptides such as vasopressin, oxytocin, ACTH, ANG I, ANG II, neurotensin, substance P, VIP, $\beta$-endorphin and Met-enkephalin.

The plasma samples were extracted with octadecilyl-silica cartridges (Sep-pak; Waters Associates, Milford, MA) with a recovery of $60 \pm 4 \%$. Extracts were dried and then reconstituted in assay buffer, the tracer used was the 3-[25I]iodotyrosyl derivative of ANF (74 TBq/ mmol; Amersham). Synthetic human ANF, purchased from Novabiochem (Laüfelfingen, Switzerland) was used for the standard curves.

After $20 \mathrm{~h}$ of incubation at $4^{\circ} \mathrm{C}$, free and bound peptide were separated by precipitation with $\gamma$-globulin $(0.25 \%)$ and polyethylene glycol (PEG 4000, 25\%). All plasma values were expressed in picograms per milliliter and corrected for $60 \%$ recovery. The smallest value of ANF detected by the assay was $1.56 \mathrm{pg} /$ tube and our standard curve ranged from 1.56 to $400 \mathrm{pg} /$ tube. The inter- and intraassay coefficients of variation were $8 \%$ and $4.5 \%$, respectively.

Normal range of plasma irANF concentrations measured in venous blood samples from 30 subjects (ranging in age from 28 to 88 $\mathrm{yr}$, mean age, $51 \mathrm{yr}$ ) in our laboratory averaged $53 \pm 24 \mathrm{pg} / \mathrm{ml}$.

$A N F$ infusion. The response to ANF infusion was studied in a subgroup of seven consecutive patients with severe COLD whose characteristics are described in Table I. These patients were selected on the basis of a mean PPA $\geq 25 \mathrm{mmHg}$.

Infusion of ANF was preceded by a baseline phase of 30 min during which two sets of measurement were performed to serve as control. The experimental infusion phase lasted $30 \mathrm{~min}$. Synthetic human ANF previously tested for apyrogenicity was diluted in $0.9 \%$ sodium chloride and was administered during three consecutive 10-min periods at the incremental infusion rates of $0.01 \mu \mathrm{g} / \mathrm{kg}$ per min, $0.03 \mu \mathrm{g} / \mathrm{kg}$ per $\mathrm{min}$ and $0.1 \mu \mathrm{g} / \mathrm{kg}$ per min via an infusion pump (Vial-Medical, Grenoble, France). Hemodynamic parameters were continuously monitored. Blood samples for gasometric measurements and plasma irANF determinations were obtained at the end of each $10 \mathrm{~min}$ infusion period, and repeated at 15 and $30 \mathrm{~min}$ of the postinfusion period. Expired gas was collected before ANF infusion and at the end of the 30-min infusion period in a Douglas bag connected to the patient via a non-rebreathing valve. Fractional concentrations of $\mathrm{O}_{2}$ and $\mathrm{CO}_{2}$ in the expired gas were measured with an ABL 30 gasometer (Radiometer) for determination of whole oxygen consumption $\left(\dot{V} \mathrm{O}_{2}\right)$ and carbon dioxide production $\left(\dot{V} \mathrm{CO}_{2}\right)$. Alveolar $\mathrm{PO}_{2}$ was calculated as $\mathrm{PAO}_{2}$ $=$ inspiratory $\mathrm{PO}_{2}-$ alveolar $\left.\mathrm{PCO}_{2}\left(\mathrm{~F}_{1} \mathrm{O}_{2}+\left(1-\mathrm{F}_{1} \mathrm{O}_{2}\right) / R\right)\right]$ where alveolar $\mathrm{PCO}_{2}$ is assumed equal to arterial $\mathrm{PCO}$, and $\mathrm{R}$ (the respiratory exchange ratio) is calculated as $\dot{V} \mathrm{CO}_{2} / \dot{V} \mathrm{O}_{2}$. From $\mathrm{PAO}_{2}$ and $\mathrm{PaO}_{2}$, the alveolar to arterial $\mathrm{O}_{2}$ gradient was calculated. The ratio of physiological dead space to tidal volume $\left(V_{\mathrm{D}} / V_{\mathrm{T}}\right)$ was computed using the Bohr equation (26).

Statistical analysis. All data are presented as mean \pm SEM. Statistical analysis for values obtained during ANF infusion was performed by analysis of variance for repeated measures, followed by a multiple range test when the $F$ value indicated significant differences among group means. Ventilatory data were compared using a Wilcoxon test. The relationships between plasma irANF concentration and other measurements were first analyzed by linear regression procedure. Multiple stepwise regression analysis was performed to evaluate factors independently related to plasma irANF concentrations (27): $P<0.05$ was considered significant.

\section{Results}

\section{Responses to ANF infusion in seven patients}

Hemodynamics. These seven patients had pulmonary artery hypertension at rest with a mean PPA of $33 \pm 3 \mathrm{mmHg}$ and PVR of $6.2 \pm 0.8 \mathrm{mmHg} / \mathrm{liter} \cdot \mathrm{min} \cdot \mathrm{m}^{2}$ ). Patient 1 was chronically treated with supplemental oxygen ( $1.5 \mathrm{liters} / \mathrm{min})$, and was subsequently investigated while receiving $25 \%$ oxygen 
Table I. Clinical and Gasometric Baseline Characteristics of Seven Patients with COLD

\begin{tabular}{|c|c|c|c|c|c|c|c|c|}
\hline Patient no. & Age & Sex & $\begin{array}{l}\text { Supplemental } \\
\text { oxygen }\end{array}$ & FVC & $\mathrm{FEV}_{1}$ & $\mathrm{PaO}_{2}$ & $\mathrm{PaCO}_{2}$ & $\mathrm{Hb}$ \\
\hline & $y r$ & & & \multicolumn{2}{|c|}{ liter } & \multicolumn{2}{|c|}{$m m H g$} & $\mathrm{~g} / 100 \mathrm{ml}$ \\
\hline 1 & 79 & $\mathbf{M}$ & + & $\begin{array}{l}2.3 \\
(73)\end{array}$ & $\begin{array}{l}1.1 \\
(49)\end{array}$ & 63 & 72 & 19 \\
\hline 2 & 54 & $\mathbf{M}$ & - & $\begin{array}{l}2.4 \\
(66)\end{array}$ & $\begin{array}{l}0.87 \\
(30)\end{array}$ & 60 & 44 & 15 \\
\hline 3 & 66 & $\mathbf{M}$ & - & $\begin{array}{l}2.3 \\
(70)\end{array}$ & $\begin{array}{l}1.1 \\
(58)\end{array}$ & 60.5 & 48 & 13.7 \\
\hline 4 & 71 & $\mathbf{M}$ & - & $\begin{array}{l}1.97 \\
(64)\end{array}$ & $\begin{array}{l}0.95 \\
(41)\end{array}$ & 48.5 & 53 & 15.5 \\
\hline 5 & 56 & $\mathbf{M}$ & - & $\begin{array}{l}1.56 \\
(36)\end{array}$ & $\begin{array}{l}0.8 \\
(27)\end{array}$ & 65 & 45.5 & 13 \\
\hline 6 & 74 & $\mathbf{M}$ & - & $\begin{array}{l}2.8 \\
(73)\end{array}$ & $\begin{array}{l}1.4 \\
(50)\end{array}$ & 49 & 57 & 16 \\
\hline 7 & 37 & $F$ & - & $\begin{array}{l}2.01 \\
(60)\end{array}$ & $\begin{array}{l}0.65 \\
(22)\end{array}$ & 57 & 50.5 & 12.9 \\
\hline
\end{tabular}

Numbers in brackets are percent of predicted normal for each value. Fraction of inspiratory oxygen tension was adjusted to $25 \%$ in patient 1 .

through a non-rebreathing valve connected to a Vespal gas blender (Air Liquide; Le Plessis-Robinson, France). The six remaining patients were breathing room air during all the
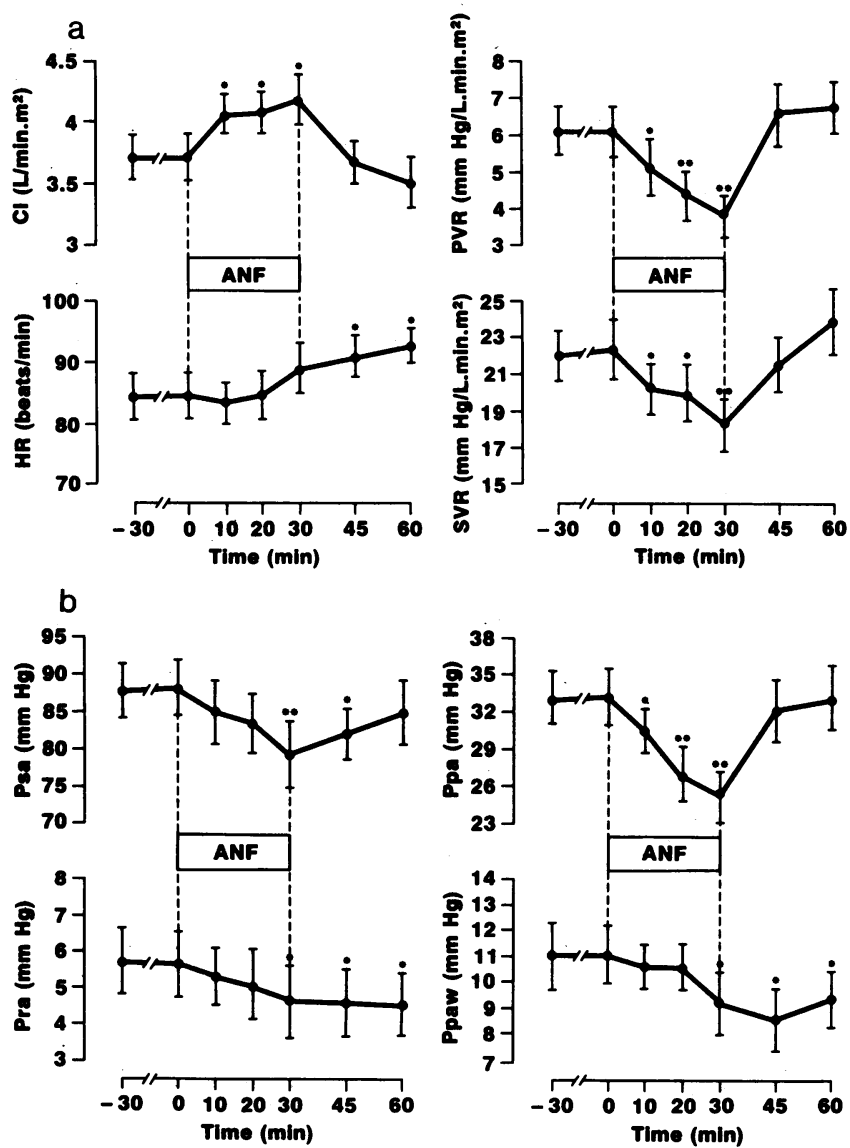

Figure 1. Hemodynamic responses to incremental infusion rates of ANF. Onset of ANF infusion is indicated by time 0 . Hemodynamic variables reported at times 10,20 , and 30 min were measured at the end of each 10-min infusion period at the incremental ANF infusion rates of $0.01,0.03$, and $0.1 \mu \mathrm{g} / \mathrm{kg} \cdot \mathrm{min}$. The ANF infusion was discontinued at time 30 . study period. The hemodynamic responses to incremental ANF infusion rates are described in Fig. 1, $a$ and $b$. Compared to control values before ANF infusion, PPA decreased in a dose-related fashion from $33 \pm 3 \mathrm{mmHg}$ to $25 \pm 2 \mathrm{mmHg}(P$ $<0.001$ ) at $0.1 \mu \mathrm{g} / \mathrm{kg} \cdot \mathrm{min}$ ANF. Systemic arterial pressure decreased significantly at $0.1 \mu \mathrm{g} / \mathrm{kg} \cdot \min$ ANF from $88 \pm 4$ $\mathrm{mmHg}$ to $79 \pm 4 \mathrm{mmHg}(P<0.001)$ while the heart rate remained unchanged ( $89 \pm 4$ bpm vs. $86 \pm 4$ bpm, NS). CI increased at any ANF infusion rate, and maximally from $3.7 \pm 0.2$ liters $/ \mathrm{min} \cdot \mathrm{m}^{2}$ to $4.2 \pm 0.2 \mathrm{liter} / \mathrm{min} \cdot \mathrm{m}^{2}(P<0.01)$ at $0.1 \mu \mathrm{g} / \mathrm{kg} \cdot \mathrm{min}$ ANF infusion. This slight increase in CI was associated to a significant increase in stroke volume index (from $43.8 \pm 3.3 \mathrm{ml} / \mathrm{m}^{2}$ to $48.2 \pm 3.6 \mathrm{ml} / \mathrm{m}^{2}, P<0.05$ ) at the ANF infusion rate of $0.01 \mu \mathrm{g} / \mathrm{kg}$ per min. Cardiac filling pressures decreased at $0.1 \mu \mathrm{g} / \mathrm{kg} \cdot \min$ ANF infusion; PPAW fell from $11 \pm 1 \mathrm{mmHg}$ to $9 \pm 1 \mathrm{mmHg}(P<0.05)$ and PRA fell from $5.5 \pm 1 \mathrm{mmHg}$ to $4.5 \pm 1 \mathrm{mmHg}(P<0.01)$. Infusion of ANF was associated with a dose-related reduction in PVR, from $6.2 \pm 0.8$ to $3.9 \pm 0.6 \mathrm{mmHg} / \mathrm{liter} \cdot \mathrm{min} \cdot \mathrm{m}^{2}(P<0.001)$ and SVR, from $22.6 \pm 1.7$ to $18.2 \pm 1.6 \mathrm{~mm} \mathrm{Hg} /$ liter $\cdot \mathrm{min} \cdot \mathrm{m}^{2}$ $(P<0.001)$. Within $30 \mathrm{~min}$ of discontinuation of the ANF infusion, CI, PSA, PPA, PVR, and SVR all returned toward baseline control values; PRA and PPAW remained lower and heart rate became higher than control values recorded before ANF infusion $(93 \pm 3$ vs. $86 \pm 5$ bpm, $P<0.02)$.

Ventilation and gas exchange. The effects produced by ANF infusion on ventilation and gas exchange are presented in Tables II and III. Arterial $\mathrm{PO}_{2}$ decreased gradually in response to incremental infusion rates of ANF (from $58 \pm 2 \mathrm{mmHg}$ to $53 \pm 2 \mathrm{mmHg}, P<0.01$ ), while mixed venous oxygen tension remained unchanged. At the end of the ANF infusion period, a significant increase of minute ventilation $(\dot{V} \mathrm{E})$ was measured (from $9 \pm 0.8 \mathrm{liters} / \mathrm{min}$ to $11.1 \pm 1.5 \mathrm{liters} / \mathrm{min}, P<0.05$ ), which appeared attributable to a slight increase in both respiratory rate and tidal volume. The mean baseline $V_{\mathrm{D}} / V_{\mathrm{T}}$ ratio for the group was markedly high, at $52.5 \pm 3.5 \%$, and slightly decreased to $48.5 \pm 3 \%(P<0.02)$ at the end of the ANF infusion period. These changes were associated with a small but insignificant increment in $\dot{V} \mathrm{O}_{2}$ and $\dot{V} \mathrm{CO}_{2}$, and the $r$ values were not significantly changed. As a consequence of the increased 
Table II. Gas Exchange Alterations in Response to ANF Infusion

\begin{tabular}{|c|c|c|c|c|c|}
\hline & \multirow[b]{2}{*}{ Control } & \multicolumn{3}{|c|}{ ANF $(\mu g / \mathrm{kg} \cdot \min )$} & \multirow[b]{2}{*}{ Recovery } \\
\hline & & 0.01 & 0.03 & 0.10 & \\
\hline $\mathrm{PaO}_{2}(m m H g)$ & $58 \pm 2$ & $54 \pm 2.5^{*}$ & $53 \pm 2.5^{\ddagger}$ & $53 \pm 2^{\ddagger}$ & $56.5 \pm 3$ \\
\hline $\mathrm{SaO}_{2}(\%)$ & $88.5 \pm 1.5$ & $86.5 \pm 1.5^{*}$ & $87 \pm 1$ & $86.5 \pm 1.5^{*}$ & $88 \pm 1.5$ \\
\hline $\mathrm{PaCO}_{2}(m m H g)$ & $53 \pm 3.5$ & $52 \pm 3$ & $50.5 \pm 3^{*}$ & $49 \pm 3^{*}$ & $48 \pm 3^{\ddagger}$ \\
\hline $\mathrm{P}^{-} \mathrm{O}_{2}(\mathrm{mmHg})$ & $35.5 \pm 1$ & $36 \pm 1$ & $36.5 \pm 1$ & $35.5 \pm 1$ & $33 \pm 1^{*}$ \\
\hline$S \overline{\mathrm{v}} \mathrm{O}_{2}(\%)$ & $66 \pm 1.5$ & $66 \pm 1.5$ & $68 \pm 1.7$ & $67 \pm 2$ & $61 \pm 1^{\ddagger}$ \\
\hline $\mathrm{pH}$ & $7.38 \pm 0.01$ & $7.39 \pm 0.01$ & $7.40 \pm 0.01^{\ddagger}$ & $7.40 \pm 0.01^{\ddagger}$ & $7.39 \pm 0.01$ \\
\hline$\dot{Q} \mathrm{va} / \dot{Q} \mathrm{t}(\%)$ & $35 \pm 3$ & $39.5 \pm 3.5$ & $41 \pm 3.5^{*}$ & $40 \pm 3^{*}$ & $31 \pm 4$ \\
\hline $\operatorname{SOT}\left(\mathrm{ml} / \mathrm{min} \cdot \mathrm{m}^{2}\right)$ & $631 \pm 19$ & $691 \pm 37$ & $679 \pm 27$ & $726 \pm 35^{*}$ & $658 \pm 46$ \\
\hline $\mathrm{Hb}(\mathrm{g} / 100 \mathrm{ml})$ & $15 \pm 0.8$ & $15.1 \pm 0.8$ & $15.1 \pm 0.8$ & $15.4 \pm 0.7^{*}$ & $15.3 \pm 0.6$ \\
\hline
\end{tabular}

Abbreviations used in this table: $\mathrm{SaO}_{2}$, arterial oxygen saturation; $S \overline{\mathrm{v}} \mathrm{O}_{2}$, mixed venous oxygen saturation; $\dot{Q}$ va/ $\dot{Q}$ t, venous admixture; $\mathrm{SOT}$, systemic oxygen transport. Data at recovery were measured 30 min after cessation of ANF infusion. Values are mean \pm SEM. ${ }^{*} P<0.05 \pm$; $\ddagger P<0.01$ with reference to control values measured before ANF infusion.

ventilation and reduction of dead space, the arterial $\mathrm{PCO}_{2}$ decreased from $53 \pm 3.5$ to $49 \pm 3 \mathrm{mmHg}(P<0.01)$ and arterial $\mathrm{pH}$ increased slightly, from $7.38 \pm 0.01$ to $7.40 \pm 0.01, P<0.01$ ). The alveolar $\mathrm{O}_{2}$ tension improved during ANF infusion from $92 \pm 5$ to $99 \pm 5 \mathrm{mmHg}(P<0.01)$, while the arterial $\mathrm{PO}_{2}$ was reduced. Consequently, the alveolar to arterial pressure gradient for oxygen widened in response to ANF infusion (from $35 \pm 4$ to $46 \pm 4 \mathrm{mmHg}, P<0.01$ ), in association with a significant increase of venous admixture (from $35 \pm 3$ to $40 \pm 3 \%, P$. $<0.05$ ). Despite the decrease in $\mathrm{PaO}_{2}$, arterial oxygen content was maintained during ANF infusion (17.1 \pm 0.5 vs. $17.4 \pm 0.5$ $\mathrm{ml} / 100 \mathrm{ml}, \mathrm{NS}$ ) because of a concomitant increase of hemoglobin concentration $(15.4 \pm 0.7$ vs. $15 \pm 0.8 \mathrm{~g} / 100 \mathrm{ml}, P$ $<0.05$ ). As a result of the concomitant increase of CI, systemic oxygen transport improved at $0.1 \mu \mathrm{g} / \mathrm{kg} \cdot \min$ ANF infusion (from $631 \pm 19$ to $726 \pm 35 \mathrm{ml} / \mathrm{min} \cdot \mathrm{m}^{2}, P<0.05$ ). Gasometric variables returned toward control values within $30 \mathrm{~min}$ after cessation of ANF infusion, except for mixed venous oxygen tension, which decreased from $35.5 \pm 1$ to $33 \pm 1 \mathrm{mmHg}$ (Table II).

Hormone levels. As the rate of ANF infusion was increased from 0.01 to 0.03 and to $0.1 \mu \mathrm{g} / \mathrm{kg} \cdot \mathrm{min}$ in the seven patients, plasma irANF concentration rose from $136 \pm 38 \mathrm{pg} / \mathrm{ml}$ before ANF infusion to $368 \pm 65 \mathrm{pg} / \mathrm{ml}, 1,323 \pm 234 \mathrm{pg} / \mathrm{ml}$ and

Table III. Ventilatory Response to ANF Infusion

\begin{tabular}{lccc}
\hline & Control & ANF & Significance \\
\hline & & $0.1 \mu \mathrm{\mu g} / \mathrm{kg} \cdot \mathrm{min}$ & \\
$\dot{V}_{\mathrm{E}}($ liters $/ \mathrm{min})$ & $9.0 \pm 0.8$ & $11.1 \pm 1.5$ & $P<0.05$ \\
$R R(\mathrm{breaths} / \mathrm{min})$ & $23 \pm 1.5$ & $26 \pm 2$ & $\mathrm{NS}$ \\
$V_{\mathrm{T}}(\mathrm{ml})$ & $380 \pm 27$ & $434 \pm 47$ & $\mathrm{NS}$ \\
$V_{\mathrm{D}} / V_{\mathrm{T}}(\%)$ & $52.5 \pm 3.5$ & $48.5 \pm 3$ & $P<0.02$ \\
$\dot{V} \mathrm{O}_{2}\left(\mathrm{ml} / \mathrm{min} \cdot \mathrm{m}^{2}\right)$ & $153 \pm 8$ & $178 \pm 16$ & $\mathrm{NS}$ \\
$\dot{V} \mathrm{CO}_{2}\left(\mathrm{ml} / \mathrm{min} \cdot \mathrm{m}^{2}\right)$ & $118 \pm 4$ & $134 \pm 11$ & $\mathrm{NS}$ \\
& & & \\
\hline
\end{tabular}

Abbreviations used in this table: $\dot{V}_{\mathrm{E}}$, minute ventilation; $R R$, respiratory rate; $V_{\mathrm{T}}$, tidal volume, $V_{\mathrm{D}} / V_{\mathrm{T}}$, ratio of dead space to tidal volume; $\dot{V} \mathrm{O}_{2}$, oxygen consumption; $\dot{V} \mathrm{CO}_{2}$, carbon dioxide production. Values are mean \pm SEM and are compared with a Wilcoxon test.
$3,589 \pm 798 \mathrm{pg} / \mathrm{ml}$, respectively (Table IV). Plasma irANF concentrations returned to baseline control values within $30 \mathrm{~min}$ of discontinuation of the infusion.

Baseline plasma renin activity was $4 \pm 2.4 \mathrm{ng} / \mathrm{ml}$ per $\mathrm{h}$ for this group of patients and remained unchanged throughout the ANF infusion period. Plasma aldosterone was $107 \pm 35 \mathrm{pg} / \mathrm{ml}$ during baseline conditions, decreased by $43 \%(P<0.05)$ during ANF infusion and remained lower than control values up to $30 \mathrm{~min}$ after discontinuation of ANF infusion (Table IV).

\section{Physiological factors related to plasma irANF concentrations}

Data obtained from the 24 patients in a steady state and resting conditions were used for the statistical analysis. Data obtained from 11 of these patients appeared in a previous report (18).

The group showed a substantial reduction in forced vital capacity $(2.1 \pm 0.21 ; 65 \pm 3 \%$ predicted $)$ and a reduction in $\mathrm{FEV}_{1}$ to $0.9 \pm 0.1$ liter, resulting in a severely reduced $\mathrm{FEV}_{1} / \mathrm{FVC}$ ratio of $39 \pm 3 \%$. Most of these patients had moderate hypoxemia (mean $\mathrm{PaO}_{2}=60 \mathrm{mmHg}$, extreme values $=49-70$ $\mathrm{mmHg}$ ). The level of carbon dioxide tension in the arterial blood was greater than normal in all but two patients in whom the oxygen tension was also near normal level. The hemoglobin concentration was $>15.5 \mathrm{~g} / 100 \mathrm{ml}$ in nine patients. Pulmonary hypertension, defined as a mean PPA $>20 \mathrm{mmHg}$ was present in all these patients and varied from mild to severe (four patients had a PPA above $35 \mathrm{mmHg}$ and five patients had PPA values $<25 \mathrm{mmHg}$ ). Pulmonary vascular resistance was increased (mean PVR $=5.5 \pm 0.4 \mathrm{mmHg} / \mathrm{liter} \cdot \mathrm{min} \cdot \mathrm{m}^{2}$ ) but systemic vascular resistance was normal (mean SVR $=24.5 \pm 1.5 \mathrm{mmHg} / \mathrm{liter} \cdot \mathrm{min} \cdot \mathrm{m}^{2}$ ).

The relationships of pulmonary arterial mean pressure to other measurements were examined by linear regression analysis: PPA was positively correlated with $\mathrm{PaCO}_{2}(r=0.48, P$ $<0.05)$ and negatively with $\mathrm{pH}(r=-0.47, P<0.05)$ or arterial $\mathrm{PO}_{2}(r=-0.51, P<0.02)$; no relationship was found between PPA and hemoglobin concentration.

Resting mean plasma irANF level was increased in these patients with COLD $(122 \pm 13 \mathrm{pg} / \mathrm{ml})$, but individual values varied from normal to markedly elevated level (48 to 274 $\mathrm{pg} / \mathrm{ml}$ ). As already reported in patients with pulmonary artery hypertension of diverse etiology (18), plasma irANF concen- 


\begin{tabular}{|c|c|c|c|c|c|}
\hline & \multirow[b]{2}{*}{ Control } & \multicolumn{3}{|c|}{ ANF } & \multirow[b]{2}{*}{ Recovery } \\
\hline & & 0.01 & 0.03 & 0.1 & \\
\hline & \multicolumn{5}{|c|}{$\mu g / k g \cdot \min$} \\
\hline ANF $(p g / m l)$ & $136 \pm 38$ & $368 \pm 65^{*}$ & $1,323 \pm 234^{*}$ & $3,589 \pm 798^{*}$ & $110 \pm 36$ \\
\hline PRA $(n g / m l / h)$ & $4 \pm 2.4$ & $3.5 \pm 2.1$ & $2.8 \pm 1.3$ & $4 \pm 2.2$ & $3.6 \pm 1.7$ \\
\hline Aldosterone $(\mathrm{pg} / \mathrm{ml})$ & $107 \pm 35$ & $89 \pm 28$ & $61 \pm 17^{*}$ & $60 \pm 16^{*}$ & $63 \pm 16^{*}$ \\
\hline
\end{tabular}

Data at recovery were measured $30 \mathrm{~min}$ after cessation of ANF infusion. Values are mean $\pm \mathrm{SEM} . * P<0.05$, with reference to control measurements.

trations varied linearly and directly with PPA $(r=0.52, P$ $<0.01$, Fig. $2 a)$ and PVR $(r=0.53, P<0.01$, Fig. $2 b)$. As individual variables, $\mathrm{PaCO}_{2}(r=0.64, P<0.001$, Fig. $2 c)$, pH $(r=-0.65, P<0.001$, Fig. $2 d)$, and hemoglobin concentration $(r=0.67, P<0.001$, Fig. $2 e$ ) had a higher correlation with plasma irANF than did PPA or PVR. Multiple regression analysis indicated that hemoglobin concentration and $\mathrm{PaCO}_{2}$ were variables independently related to plasma irANF levels. They accounted for $65 \%$ of the variance in plasma irANF and hemoglobin was the major contributing factor $\left(R^{2}=43 \%\right)$. Mean values for plasma renin activity $(4.5 \pm 1.6 \mathrm{ng} / \mathrm{ml} \cdot \mathrm{h})$ and plasma aldosterone $(86 \pm 13 \mathrm{pg} / \mathrm{ml})$ were increased and also varied widely among patients. Plasma renin activity and plasma aldosterone did not correlate with plasma irANF or with other physiologic variables, whereas they were related to each other $(r=0.54, P<0.01)$.

\section{Discussion}

This study demonstrates that administration of synthetic human ANF to patients with chronic obstructive lung disease and pulmonary hypertension caused vasodilation in both the pulmonary and systemic circulation. Associated features included increase of cardiac output, reduction of cardiac filling pressures, alterations in gas exchange, increased ventilation, evidence of hemoconcentration, and suppression of aldosterone.

Study of physiological correlates of plasma irANF levels in 24 patients with COLD revealed positive relationships between the peptide level and the degree of hemoconcentration, respiratory acidosis, and pulmonary artery hypertension.

In patients with chronic pulmonary artery hypertension from diverse etiology, the plasma concentrations of irANF were found to be elevated in proportion to the level of pulmonary artery pressure and pulmonary vascular resistance (18). In animals exposed to chronic hypoxia and developing pulmonary hypertension, increased plasma ANF levels have also been measured in association to decreased right atrial ANF content (28). The physiologic relevance of these findings, however, has not been clarified. Results obtained from previous experimental studies of acute hypoxic pulmonary hypertension have documented a potent pulmonary vasodilating activity of $\operatorname{ANF}(24,25)$, and suggested that endogenous ANF could oppose the pulmonary pressor response to hypoxia. Thus, the enhanced release of ANF in response to an elevated pulmonary artery pressure may appear as an appropriate physiologic response that could limit the increased pressure load developed on the right ventricle during hypoxia.
Patients with COLD usually develop pulmonary hypertension as a consequence of chronic hypoxic vasoconstriction (29). The degree of pulmonary hypertension thus usually parallels the severity of hypoxemia in this disease (30), as also observed in the present study. To investigate the potential effects of ANF on the human pulmonary circulation, we studied the responses to ANF administration at incremental infusion rates in a subgroup of seven patients with severe COLD and pulmonary hypertension. The onset of action of ANF was rapid in these patients, and pulmonary artery pressure fell within minutes after starting infusion of ANF at the lowest rate. The subsequent decrease of both pulmonary and systemic arterial pressures appeared dose related. The hypotensive effects of ANF observed at the highest infusion rate, however, could partly result from a delayed response to the lowest infusion rate, as previously suggested by experimental studies (31). Cardiac index increased at any ANF infusion rate because of a concomitant increase in stroke volume index, while heart rate remained unchanged. The hemodynamic response to ANF infusion in our patients thus differs from that obtained in normotensive and some hypertensive animal models in which a significant reduction of blood pressure has been ascribed to a reduction of cardiac output rather than to a peripheral vasodilation (32-37). In humans, peripheral vasodilation and increased cardiac output in response to ANF infusion have been observed in patients with congestive heart failure $(9,17)$ but not in normal subjects (9). A pronounced vasodilatory effect of ANF has however been demonstrated in normal subjects during infusion of the peptide into the brachial artery (38), suggesting that the lack of systemic vasodilation during ANF infusion in normal man may result from reflex compensatory mechanisms to maintain blood pressure in face of the decreased cardiac output $(9,38)$.

A reduction of cardiac filling pressures probably explains such a decrease in stroke volume and cardiac output during ANF infusion $(32,36,39)$. In our patients, right atrial pressure and pulmonary arterial wedge pressure decreased during 0.1 $\mu \mathrm{g} / \mathrm{kg} \cdot \mathrm{min}$ ANF infusion, but remained within physiological range. Stroke volume index and cardiac output therefore increased as a consequence of a lowering of pulmonary and systemic vascular resistance. The maximal decrease of resistance in the pulmonary vascular bed $(-35 \%)$ exceeded that in the systemic circulation $(-25 \%)$, suggesting that the vasodilatory activity of ANF predominated in the pulmonary circulation in our patients. These results are consistent with those previously obtained in experimental animals studied during hypoxic pulmonary hypertension (25). The high sensitivity of pulmonary arteries to ANF was also suggested from studies 

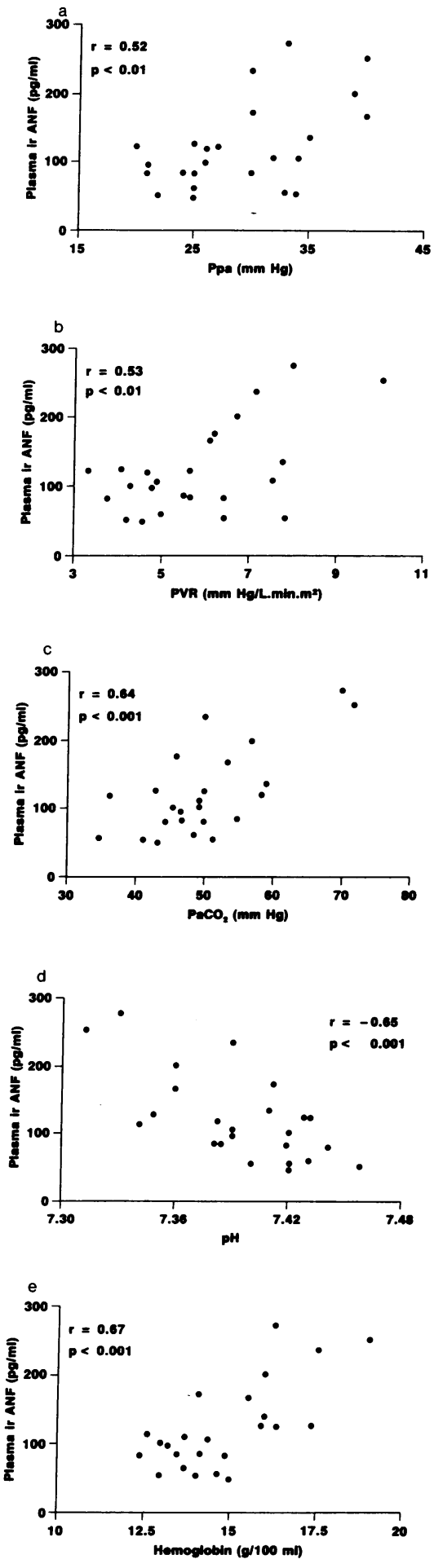

Figure 2. Plasma irANF concentrations plotted as a function of: $(a)$ mean pulmonary artery pressure (Ppa); $(b)$ pulmonary vascular resistance (PVR); (c) arterial carbon dioxide tension $\left(\mathrm{PaCO}_{2}\right) ;(d) \mathrm{pH}$; and $(e)$ hemoglobin concentration in 24 patients with COLD.

performed on isolated vascular preparations, in which the relaxant activity of ANF was found 10 times more potent on pulmonary arteries than on renal arteries (23).

Because we showed in a previous study that a measurable pulmonary vasodilating effect of ANF could only be demonstrated when the pulmonary vascular tone was enhanced by hypoxia (25), it may be assumed that pulmonary vasodilation in our patients with COLD mainly resulted from attenuation of hypoxic pulmonary vasoconstriction. If ANF decreases hy- poxic pulmonary vasoconstriction, it can also be expected to increase perfusion of poorly ventilated lung units and to worsen hypoxemia in patients with chronic lung disease. In our patients, ANF lowered arterial $\mathrm{Po}_{2}$ despite a concomitant increase of minute ventilation. Alveolar to arterial oxygen gradient widened and venous admixture increased, likely reflecting alterations in ventilation-perfusion relationships as a consequence of reversal of hypoxic pulmonary vasoconstriction. The increased ventilation may have resulted from the decrease in both arterial $\mathrm{PO}_{2}$ or blood pressure via some central stimulatory effect. A direct bronchodilating effect of ANF may also be implicated in this response (40). Further study will therefore be required to clarify the mechanism of ANF-induced increased ventilation in patients with COLD.

Despite the slight decrease in $\mathrm{PaO}_{2}$, oxygen transport was maintained or even increased at $0.1 \mu \mathrm{g} / \mathrm{kg} \cdot \min$ ANF infusion because of a concomitant increase in cardiac output and a slight but significant increase in hemoglobin concentration. An elevation of hemoglobin concentration has often been reported in response to ANF infusion $(1,9,32)$ and may result from volume contraction induced by fluid loss through diuresis. A shift of fluid from the vascular to the extravascular space has also been suggested as an additional mechanism to explain this effect $(9,33,35)$, and indirect evidence was recently provided in rats that ANF could decrease capillary absorption because of increased capillary hydrostatic pressure (41).

Plasma renin activity and aldosterone levels are usually increased in patients with COLD, especially when hypoxia and hypercapnia are present $(42,43)$. In our patients, the infusion of ANF led to a significant reduction in aldosterone levels and to a slight but insignificant decrease in plasma renin activity. These results are consistent with earlier experiments showing that ANF decreases plasma renin and aldosterone in animals and humans $(9,32,44)$ and inhibits aldosterone production in vitro (45).

An important question raised by these findings is whether endogenous ANF could produce similar alterations in patients with COLD at physiological levels. In our patients, while the response to ANF was of greater magnitude at the highest infusion rate, significant effects already occurred at the lowest ANF infusion rate $(0.01 \mu \mathrm{g} / \mathrm{kg}$ per min). Baseline plasma irANF concentration ranged from 50 to $250 \mathrm{pg} / \mathrm{ml}$ before infusion and from 170 to $566 \mathrm{pg} / \mathrm{ml}$ during $0.01 \mu \mathrm{g} / \mathrm{kg} \cdot \mathrm{min}$ ANF infusion. It therefore appears that measurable effects of ANF could be detected in some patients at plasma irANF levels in the range observed during baseline condition in patients with more severe disease.

The demonstration that an acute change in plasma ANF concentrations could affect pulmonary hemodynamics, gas exchange, ventilation, and hormonal levels in patients with COLD led us to examine the relationships of related parameters on the modulation of ANF secretion in a larger group of patients. A significant correlation was found between plasma irANF concentration and the degree of hemoglobin concentration, respiratory acidosis, and pulmonary hypertension. No relationship was found between plasma irANF and plasma renin activity or aldosterone as also reported in patients with congestive heart failure (16). Since the group of patients was homogenous in most respects, the data are therefore of value when considering the effects of disturbances of these physiological parameters on plasma irANF levels and on their interrelation in COLD. The predominant stimulus affecting ANF 
secretion is direct atrial stretch (5). Since volume overloading, or other maneuvers which acutely increase atrial stretch, increase ANF secretion (6-8), it seems probable that a chronic increase in atrial wall tension contributed to the elevation of plasma irANF concentrations in our patients with COLD. Although we did not find any relationship between plasma irANF concentrations and right atrial pressure, or pulmonary arterial wedge pressure, a positive correlation was found between plasma irANF and PPA or PVR, similarly to results obtained in previous studies (18). Both pulmonary artery pressure and red cell volume have been shown to reflect central blood volume in patients with COLD, while no relationship has been found between cardiac filling pressures and central blood volume (46). These observations are consistent with our findings of a correlation between plasma irANF levels and pulmonary artery pressure or hemoglobin concentration but not with cardiac filling pressures in such patients. These findings would also suggest that polycythemia might have contributed to stimulate ANF secretion in our patients via an increase in both central blood volume and pulmonary artery pressure $(46,47)$.

The degree of hypercapnic acidosis appeared as another important physiological stimulus for ANF secretion in patients with COLD. Respiratory acidosis may influence ANF secretion through several potential mechanisms: (a) respiratory acidosis has been shown to potentiate the pulmonary pressor response to hypoxia (30), which may account for the positive correlation between $\mathrm{PaCO}_{2}$ and pulmonary artery pressure found in our patients and in other studies (30). Respiratory acidosis could thus increase ANF secretion partly by increasing vasoconstriction in the pulmonary circulation; $(b)$ hypercapnia may also negatively influence sodium excretion in patients with COLD, either directly, via a renal tubular effect (48), or indirectly, via a decreased renal blood flow mediated by alpha adrenergic stimuli (43). These renal effects may result in extracellular fluid volume expansion, which may in turn increase ANF secretion; and (c) evidence was recently provided that both alpha and beta adrenergic agonists could stimulate ANF secretion (49-51), suggesting an involvement of the sympathetic nervous system in the physiologic regulation of ANF secretion. An increased sympathetic tone associated to hypercapnia (52) may also have contributed to enhance ANF secretion in our patients.

Current evidence suggests that the major effects of ANF are to promote loss of fluid and electrolytes, to reduce vascular tone, and to suppress aldosterone secretion. These combined actions of the peptide are expected to reduce atrial stretch, and therefore reduce the secretory stimulus to prevent additional hormone release as a consequence of a negative feedback mechanism. We found polycythemia, respiratory acidosis, and pulmonary hypertension to closely correlate with circulating ANF levels in patients with COLD. These physiological disturbances in this disease may reflect central blood volume overload, impaired renal excretory function, and increased pulmonary vascular resistance. Subsequent elevation of circulating ANF could serve as a protective mechanism against such physiological abnormalities. In addition to its diuretic, natriuretic and antialdosterone actions, ANF could limit the pulmonary hypertension of patients with COLD by a direct negative influence on the pulmonary vascular tone. This latter effect may however adversely affect gas exchange because of subsequent alterations in ventilation-perfusion relationships.
The present study thus suggests that ANF could play an important role in the maintenance of the circulatory homeostasis in patients with COLD and could limit their pulmonary hypertension.

\section{Acknowledgments}

The authors wish to thank Mr. Robert Herigault and Mrs. Bernadette Gaujour for their technical assistance and Mrs. Martine Roulet for her assistance in preparation of this manuscript.

\section{References}

1. De Bold, A. J., H. B. Borenstein, A. T. Veress, and H. Sonnenberg. 1981. A rapid and potent natriuretic response to intravenous injection of atrial myocardial extracts in rats. Life Sci. 28:89-94.

2. Cantin, M., and J. Genest. 1985. The heart and the atrial natriuretic factor. Endocr. Rev. 6:107-127.

3. Laragh, J. H. 1985. Atrial natriuretic hormone, the renin-aldosterone axis, and blood pressure electrolyte homeostasis. $N$. Engl. J. Med. 313:1330-1340.

4. Needleman, P., S. P. Adams, B. R. Cole, M. G. Currie, D. M. Geller, M. L. Michener, C. B. Saper, D. Schwartz, and D. G. Standaert. 1985. Atriopeptins as cardiac hormones. Hypertension. 7:469-482.

5. Dietz, J. R. 1984. Release of atrial natriuretic factor from rat heart-lung preparation by atrial distension. Am. J. Physiol. 247:R 1093-1096.

6. Lang, R. E., H. Tholken, D. Ganten, F. C. Luft, H. Ruskoaho, and T. Hunger. 1985. Atrial natriuretic factor: a circulating hormone stimulated by volume loading. Nature (Lond.). 314:264-266.

7. Epstein, M., R. Loutzenhiser, E. Friedland, R. M. Aceto, M. J. F. Camargo, and S. A. Atlas. 1987. Relationship of increased plasma atrial natriuretic factor and renal sodium handling during immersioninduced central hypervolemia in normal humans. J. Clin. Invest. 79:738-745.

8. Yamaji, T., M. Ishibashi, and F. Takaku. 1985. Atrial natriuretic factor in human blood. J. Clin. Invest. 76:1705-1709.

9. Cody, R. J., S. A. Atlas, J. H. Laragh, S. H. Kubo, A. B. Covit, K. S. Ryman, A. Shaknovich, R. Pondolfino, M. Clark, M. J. F. Camargo, R. M. Scarborough, and J. A. Lewicki. 1986. Atrial natriuretic factor in normal subjects and heart failure patients. J. Clin. Invest. 78:1362-1374.

10. Tikkanen, I., F. Fyhrquist, K. Metsärinne, and R. Leidenius. 1985. Plasma atrial natriuretic peptide in cardiac disease and during infusion in healthy volunteers. Lancet. ii:66-69.

11. Richards, A. M., M. G. Nicholls, H. Ikram, M. W. I. Webster, T. G. Yandle, and E. A. Espiner. 1985. Renal, hemodynamic, and hormonal effects of human alpha atrial natriuretic peptide in healthy volunteers. Lancet. i:545-549.

12. Weidmann, P., L. Hasler, M. P. Gnädinger, R. E. Lang, D. E. Vehlinger, S. Shaw, W. Rascher, and F. C. Reubi. 1986. Blood levels and renal effects of atrial natriuretic peptide in normal man. J. Clin. Invest. 77:734-742.

13. Waldhausl, W., H. Vierhapper, and P. Nowotny. 1986. Prolonged administration of human atrial natriuretic peptide in healthy men. Evanescent effects of diuresis and natriuresis. J. Clin. Endocrinol. Metab. 62:956-959.

14. Biollaz, J., J. Nussberger, M. Porchet, F. Brunner-Ferber, E. S. Otterbein, H. Gomez, B. Waeber, and R. H. Brunner. 1986. Fourhours infusions in synthetic atrial natriuretic peptide in normal volunteers. Hypertension (Dallas). 8(suppl. II):II-96-II-105.

15. Raine, A. E. G., P. Erne, E. Bürgisser, F. B. Müller, P. Bolli, F. Burkart, and F. R. Bühler. 1986. Atrial natriuretic peptide and atrial pressure in patients with congestive heart failure. N. Engl. J. Med. 315:533-537. 
16. Shenker, Y., R. S. Sider, E. A. Ostafin, and R. J. Grekin. 1985. Plasma levels of immunoreactive atrial natriuretic factor in healthy subjects and in patient with edema. J. Clin. Invest. 76:1684-1687.

17. Saito, Y., K. Nakao, K. Nishimura, A. Sugawara, K. Okumura, K. Obata, R. Sonoda, T. Bon, H. Yasue, and H. Imura. 1987. Clinical application of atrial natriuretic polypeptide in patients with congestive heart failure: beneficial effects on left ventricular function. Circulation. 76:115-124.

18. Adnot, S., P. E. Chabrier, P. Andrivet, I. Viossat, J. Piquet, C. Brun-Buisson, Y. Gutkowska, and P. Braquet. 1987. Atrial natriuretic peptide concentrations and pulmonary hemodynamics in patients with pulmonary artery hypertension. Am. Rev. Respir. Dis. 136:951956.

19. Olins, G. M., D. R. Pattron, F. S. Tjoeng, D. J. Blehm. 1986. Specific receptors for atriopeptin III in rabbit lung. Biochem. Biophys. Res. Commun. 140:302-307.

20. Bianchi, C., J. Gutkowska, G. Thibault, R. Garcia, J. Genest, M. Cantin. Radioautographic localization of 125-I-atrial natriuretic factor (ANF) in rat tissue. Histochemistry. 82:441-452.

21. Weselcouch, E. O., W. R. Humphrey, and J. W. Aiken. 1985. Effect of pulmonary and renal circulations on activity of atrial natriuretic peptide. Am. J. Physiol. 249:R595-R602.

22. Ignarro, L. J., K. S. Wood, R. G. Harbison, and P. J. Kadowitz. 1986. Atriopeptin II relaxes and elevates CGMP in bovine pulmonary artery but not vein. J. Appl. Physiol. 60:1128-1133.

23. Jansen, T. L. Th. A., A. H. Morice, and M. J. Brown. 1987. A comparison of the vasodilator responses to atrial peptides in the pulmonary and renal arteries of the pig in vitro. Br. J. Pharmacol. 91:687-691.

24. Will, D. H., and M. A. Council. 1986. Atriopeptin III: a pulmonary vasodilator in experimental hypoxic pulmonary hypertension. Fed. Proc. 45:2341. (Abstr.)

25. Adnot, S., P. E. Chabrier, C. Brun-Buisson, I. Viossat, P. Braquet. 1988. Atrial natriuretic factor (ANF) attenuates the pulmonary pressor response to hypoxia. J. Appl. Physiol. 65:1975-1983.

26. Bohr, C. 1891. Veber die Lungenathmung. Scand. Arch. Physiol. 2:236-268.

27. Dixon, W. J., M. B. Brown, L. Angelman, J. W. Frane, M. A. Hill, R. Sennrich, and J. D. Toporek. 1985. BMDP statistical software. University of California Press, Berkeley, CA.

28. McKenzie, J. C., I. Tanaka, T. Inagami, K. S. Misono, and R. M. Klein. 1986. Alterations in atrial and plasma atrial natriuretic factor (ANF) content during development of hypoxia-induced pulmonary hypertension in the rat. Proc. Soc. Exp. Biol. Med. 181:459-463.

29. Fishman, A. P. 1976. Chronic cor pulmonale. Am. Rev. Respir. Dis. 114:775-794.

30. Enson, Y., C. Giuntini, M. L. Lewis, T. Q. Morris, M. I. Ferrer, and R. M. Harvey. 1964. The influence of hydrogen ion concentration and hypoxia on the pulmonary circulation. J. Clin. Invest. 43:11461161.

31. Bie, P., B. C. Wang, R. J. Leadley, and K. L. Goetz. 1988. Hemodynamic and renal effects of low-dose infusion of atrial peptide in awake dogs. Am. J. Physiol. 254:R161-R169.

32. Maack, T., O. N. Marcon, M. J. F. Camargo, H. D. Kleinert, J. H. Laragh, E. O. Vaughan, Jr., and S. A. Atlas. 1984. Effects of auriculin (atrial natriuretic factor) on blood pressure, renal function, and the renin aldosterone system in the dog. Am. J. Med. 77:10691075.

33. Allen, D. E., and M. G. Gellai. 1987. Cardioinhibitory effects of atrial peptide in conscious rats. Am. J. Physiol. 252:R610-616.

34. Lappe, R. N., J. F. M. Smits, J. A. Todt, J. J. M. Debets, and R. L. Wendt. 1985. Failure of atriopeptin II to cause arterial vasodilation in the conscious rat. Circ. Res. 56:606-612.
35. Sasaki, A., O. Kida, K. Kangawa, H. Matsuro, and T. Tanaka. Involvement of sympathetic nerves in cardiosuppressive effects of alpha-human atrial natriuretic polypeptide in anesthetized rats. Eur. $J$. Pharmacol. 120:345-349.

36. Breuhaus, B. A., H. H. Sanch, M. A. Brandt, and J. E. Chimoskey. 1985. Atriopeptin II lowers cardiac output in conscious sheep. Am. J. Physiol. 249:R776-R780.

37. Volpe, M., R. E. Sosa, F. B. Muller, M. J. F. Camargo, N. Glorioso, J. H. Laragh, T. Maack, and S. A. Atlas. 1986. Differing hemodynamic responses to atrial natriuretic factor in two models of hypertension. Am. J. Physiol. H871-H878.

38. Fugita, T., Y. Ito, H. Noda, Y. Sato, K. Ando, K. Kangawa, and H. Matsuo. 1987. Vasodilatory actions of $\alpha$-human atrial natriuretic peptide and high $\mathrm{Ca}^{++}$effects in normal man. J. Clin. Invest. 80:832840.

39. Chien, Y. M., E. D. Frohlich, and N. C. Trippodo. 1987. Atrial natriuretic peptide increases resistance to venous return in rats. $\mathrm{Am}$. J. Physiol. 252:H894-H899.

40. Hand, J. M., I. M. Englebach, and R. W. Lappe. 1988. Anaritide [human atrial natriuretic factor (102-126)] as a bronchodilator in the anesthetized guinea-pig. Am. Rev. Respir. Dis. 137:28. (Abstr.)

41. Trippodo, N. C., and R. W. Barbee. 1987. Atrial natriuretic factor decreases whole-body capillary absorption in rats. Am. J. Physiol. 252:R915-R920.

42. Farber, M. O., S. S. O. Kiblawi, R. A. Strawbridge, G. L. Robertson, M. H. Weinberger, and F. Manfredi. 1977. Studies on plasma vasopressin and the renin-angiotensin-aldosterone system in chronic obstructive lung disease. J. Lab. Clin. Med. 90:373-380.

43. Farber, M. O., L. R. Roberts, M. H. Weinberger, G. L. Robertson, N. S. Fineberg, and F. Manfredi. 1982. Abnormalities of sodium and water handling in chronic obstructive lung disease. Arch. Intern. Med. 142:1326-1330.

44. Burnett, J. C. Jr, J. P. Granger, and T. S. Opgenorth. 1984. Effects of synthetic atrial natriuretic factor on renal function and renin release. Am. J. Physiol. 247:H863-H866.

45. De Lean, A., K. Racz, J. Gutkowska, T. T. Nguyen, M. Cantin, and J. Genest. 1984. Specific receptor-mediated inhibition by synthetic atrial natriuretic factor of hormone stimulated steroidogenesis in cultured bovine adrenal cells. Endocrinology. 115:1636-1638.

46. Segel, N., and J. M. Bishop. 1966. The circulation in patients with chronic bronchitis and emphysema at rest and during exercise, with special reference to the influence of changes in blood viscosity and blood volume on the pulmonary circulation. J. Clin. Invest. 45:15551568.

47. Weisse, A. B., C. B. Moschos, M. J. Frank, G. E. Levinson, J. E. Cannilla, and T. J. Regan. 1975. Hemodynamic effects of staged hematocrit reduction in patients with stable cor pulmonale and severely elevated hematocrit levels. Am. J. Med. 58:92-98.

48. Polak, A., G. W. Haynie, R. Hays, and W. B. Schwartz. 1961. Effect of chronic hypercapnia on electrolyte and acid-base equilibrium. J. Clin. Invest. 40:1223-1237.

49. Currie, M. G., and W. H. Newman. 1986. Evidence for $\alpha_{1^{-}}$ adrenergic receptor regulation of atriopeptin release from the isolated rat heart. Biochem. Biophys. Res. Commun. 137:94-100.

50. Schiebinger, R. J., M. Z. Baker, and J. Linden. 1987. Effect of adrenergic and muscarinic cholinergic agonists on atrial natriuretic peptide secretion by isolated rat atria. J. Clin. Invest. 80:1687-1691.

51. Sanfield, J. A., Y. Shenker, R. J. Grekin, and S. G. Rosen. 1987. Epinephrine increases plasma immunoreactive atrial natriuretic hormone levels in humans. Am. J. Physiol. 252:E740-E745.

52. Tenney, S. M. 1956. Sympatho-adrenal stimulation by carbon dioxide and the inhibitory effect of carbonic acid on epinephrine response. Am. J. Physiol. 187:341-347. 